\title{
Identification of strategies for collaboration of medical librarians with family physicians in advancing the goals of the family physician program based on experts' viewpoints
}

\author{
Hasan Ashrafi-Rizi, ${ }^{1}$ Mahdi Amraei, ${ }^{1}$ Hossein Kargar, ${ }^{1}$ Zahra Ghazavi, ${ }^{2}$ and Zahra Kazempour ${ }^{3}$
}

\author{
'Medical Library and Information Science, Health Information Technology Research Center, Isfahan University of Medical Sciences, Isfahan, Iran. \\ ${ }^{2}$ Medical Library and Information Science, Iran University of Medical Sciences, Tehran, Iran. \\ 32Department of Knowledge and Information Science, Payame Noor University, Tehran, Iran. \\ Correspondence to Hasan Ashrafi-Rizi (email: hassanashrafi@mng.mui.ac.ir). \\ (Submitted: 08 May 2019 - Revised version received: 21 May 2019 - Accepted: 16 June 2019 - Published online: 26 August 2019)
}

\begin{abstract}
Objective The present study was carried out with the aim of identifying ways of collaboration of medical librarians with family physicians in advancing the goals of the family physician program based on the views of experts.

Methods This research was qualitative content analysis. The statistical population included experts in the fields of family physicians. Sampling method was targeted and in order to identify qualified people, snowball sampling was used as well. The data collection tool was semi-structured interview, and the researchers exploited thematic analysis in the data analysis. To determine the validity and reliability, the Lincoln and Guba method was used based on four criteria of credibility, transferability, conformability and dependability.

Results Regarding the common areas of medical librarians and family physicians, four concepts were extracted including helping physicians in scientific and professional mastering, upgrading research methodology, upgrading information literacy, and the content of information resources for patient training. Moreover, four concepts were identified: appropriate policy-making, education suitability, participation in clinical research, and promotion of the quality of patient training in addition to six components of interaction strategies.

Conclusion Strategies for the interaction of medical librarians with family physicians can become practical in areas such as proper policymaking, suitability of education, participation in clinical research, and the improvement of the quality of patient training.

Keywords collaboration strategies, family physicians, family physician program, medical librarians
\end{abstract}

\section{Introduction}

The national family physician program was launched with the aim of establishing social justice and promoting family health as well as reducing the cost of treatment in Iran. This program plays a pivotal role in all health system programs, and its proper implementation and achievement of its goals can ensure the achievement of high-level health indicators. ${ }^{1}$ The family physician places the patients in the referral system and supervises them from the time they are admitted to the system until the end of treatment and post-treatment care. ${ }^{2}$

The service package in the family physician program includes prevention, health promotion, initial treatment and emergency management, referral, and health management. ${ }^{1}$ In summary, the family physician program is performed to control the costs of repetitive services, increase accountability against patients, track services provided to patients, establish an electronic health record for the community individuals, increase the ability to control the quality of services and establish financial discipline, and direct the patients in the three levels of the service delivery system in a fully guided manner centered by the family physician. Family physicians need to be trained to provide high-quality services.

The results of a study by Asadi showed that the knowledge and skills of family physicians are not sufficient to meet the expectations of the health system, and it is necessary to enhance the level of information and skills of physicians by holding workshops. In this study, the most important family physician weaknesses were the information gap between providers and recipients of information, lack of specialized training for the health team, especially physicians, and the inadequacy of culture-building and informing the public. ${ }^{1}$ In the study by Movahedi et al., ${ }^{3}$ lack of sufficient time to meet the specialized information by the physicians was the main reason for their need for the up-to-date information seeker, i.e. the medical librarians.

In the study by Habibi et al., ${ }^{4}$ the main reasons for failure to use electronic resources by general practitioners were lack of familiarity with the Internet, electronic resources, and medical databases, and general practitioners need to learn the Internet, tools, and methods of searching the web and medical databases. In the study by Rahimianfar et al., ${ }^{5}$ it was shown that nurses understood the need for up-to-date information, but barriers such as lack of time and lack of familiarity with resources responding to their requirements caused them not to be able to seek information. The results of the investigation by Papi et al. indicated that the information needs of physicians included conducting research, preparing articles, obtaining new and up-to-date information, managing patient care, teaching, and performing everyday tasks. However, physicians' lack of comprehensive knowledge of electronic information resources has led to less use of such resources. ${ }^{6}$ Findings by Ciarlo et al. revealed that general practitioners prefer textbooks, and oncologists prefer magazines and the Internet to meet their information requirements. Moreover, based on the results, the causes of uncertainty during the patient counseling session were lack of time, knowledge and information. In fact, oncologists choose different ways to access information. ${ }^{7}$ Findings in the study by Traver et al. ${ }^{8}$ showed that physicians need a set of capabilities, organizational resources, and knowledge to acquire accurate digital literacy skills to help patients. The findings by Bryant revealed that family physicians had to seek information to address their 
specialized needs including information on patient care, and use medical libraries less. Nevertheless, they believed that using the potential of medical librarians is very effective in the work process. Therefore, it can be claimed that medical librarians can play an effective role in meeting the information needs of family physicians. ${ }^{9}$ Besides, the results of some studies indicate that over $40 \%$ of patients did not receive best-evidence-based care, and more than $20 \%$ of them received inadequate or inappropriate care. ${ }^{10}$ Today, the health system should be safe, patient-centered, based on the best evidence and according to the patient's values, and in the meantime, the doctor is responsible for maintaining the patient's health and should complete the different stages of his patients' treatment based on the latest scientific evidence. However, there is a gap between what the physicians do and what they should do in their daily practice, ${ }^{11}$ and despite the development of medical knowledge over the past years, ${ }^{12}$ there are still reports released about medical errors, endangering the lives of patients, and hence increased health care costs.

Given the investigations, it seems that the health sector has a special focus on information in all its dimensions including education, research, and treatment, and at all levels of individuals including policy-makers and health care providers and receivers. In this way, immediate access to valid and up-to-date information is indisputable for making correct decisions. ${ }^{13}$ In short, lack of physicians' access to appropriate information causes a reduction in the quality of health services, an increase in health care costs for the patient and the health system, endangering the lives of patients, and the reduction of patient confidence in the health system. Therefore, using the knowledge and skills of medical librarians by physicians will be very effective in dealing with various occupational issues.

Medical librarians, in addition to communicating with academic communities, have close links with patients and information seekers. In fact, medical librarians have a great mission in the health system by providing access to information, and help all institutions, organizations, and individuals whose main goals are specifically to protect and improve the health of individuals and society with one of these groups in the health system being family physicians. Moreover, the health system is one of the most important parts constantly evolving under the influence of technological advances. In this area, the need for the dissemination and use of high quality health information in the field of education, research, and health care, on the one hand, and the change in the storage and retrieval of information, on the other hand, has made the presence of medical librarians essential in this field. Medical librarians play an active role in the continuous education and modernity of information of the treatment team through presence in various sectors of the health system, ${ }^{14}$ and the family physician program is no exception.

Now, given the above issues, the basic question is raised: How can medical librarians play their role by utilizing their ability to meet the educational and information needs of the family physician program? And what are these roles? The family physician program will be successful when the basis for decisions in the education, research, treatment, and even management of the program is valid and up-to-date health information. Family physicians need to use the potential and capabilities of medical librarians due to lack of adequate time, and sometimes the inability to seek and evaluate the information they need. So far, there has been no study in Iran regarding the cooperation between medical librarians and family physicians. Therefore, in this study, in addition to identifying these roles, it was decided to provide the necessary ground for using the capabilities of the medical librarians in the family physician program. Therefore, the purpose of this study was to identify strategies for collaboration between medical librarians with family physicians in advancing the goals of the family physician program.

\section{Materials and Methods}

This research was qualitative content analysis. The statistical population included experts in the fields of family physicians, general practitioners in clinics and health centers, and medical librarians who were well informed about the family physician or who owned scientific works in this field in addition executive directors working in the field of family physician in Iran. Sampling method was purposeful and in order to identify qualified people, snowball sampling was used as well (10 participants remained after data saturation). The data collection tool was semi-structured interview. After identifying the samples, the time and place of the interview were coordinated and, before any interview, informed consent was received regarding participation in the interview. Data saturation occurred through interviewing with 10 people. During the interview, the interviewer also took notes, all of which were used in the data analysis process. Researchers used thematic analysis in the data analysis. In this way, each topic was read several times and a code was assigned to each topic in the end. Similar codes formed a component on a more abstract level, which were more general than the original code, and eventually the same concepts were combined and, with more abstraction, the main concepts were formed. The data analysis method was manually executed. In order to determine the validity and reliability, the Lincoln and Guba method was used based on four criteria of credibility, transferability, conformability, and dependability. ${ }^{15}$ For data credibility, the researcher used the peer debriefing and providing the results for the participants. For data transferability, the researchers described the phenomenon in question thoroughly, and explained the research conditions and details of the procedure. In addition, for conformability, they accurately and thoroughly noted and reported the interview process, data collection, decision-making, and interpretations. For data dependability, the researchers' notes were provided to peers outside the study (referees) during the interviews. The work process was also provided to the peers, and they were asked to express their views on the results. At the same time, the participants in the study entered the interview with satisfaction and could easily leave the interview at any time.

\section{Results}

The present study was carried out with the aim of identifying the strategies of collaboration of medical librarians and family physicians in advancing the goals of the family physician program. The results of the analysis led to the creation of eight concepts and 15 components.

Findings regarding the common areas between medical librarians and family physicians to advance the goals of the family physician program resulted in the following four concepts. 


\section{Scientific and Professional Mastering}

The knowledge and skills of family physicians in achieving the goals of the family physician program are called the scientific and professional mastering. In fact, access to and use of clinical information is one of the main requirements of this concept. Family physicians should be able to use the latest scientific findings to upgrade their specialized knowledge and skills. Participants stated that family physicians should be informed of the patients' lifestyles, the use of medications, the recognition of the basic principles of family health, environmental harmful factors, the epidemiological study of diseases, the recognition of various diseases, knowledge of common diseases, patient screening, etc. (Table 1).

\section{Upgrading Research Methodology}

The research methodology is a set of factors used by researchers to solve the research problem in a precise and systematic way. Family physicians should themselves perform research for better prevention, diagnosis, treatment, and rehabilitation of patients, and performing high quality research requires exploiting various specialized fields including medical librarians. In this regard, participants pointed out some of their needs including more familiarity with the research process, conducting research in specific fields, conducting systematic research, understanding the information needs, the need for research colleague, recognition of modern technologies in conducting research, unwillingness to perform research, and the need for individual education, and stated that the presence of medical librarians can help them in the research (Table 1).

\section{Improving Information Literacy}

The ability to identify information needs, find information, and evaluate and effectively use information is called the information literacy. Participants declared that they needed help from medical librarians in searching for information resources, using new technologies in accessing information, evaluating information resources, searching for specific topics, searching for work tasks, correct information, and information updating practices (Table 1).

\section{Content of the Patient Training Information Resources}

High-quality information to improve the health of the general public is one of the main tools used by family physicians. However, in the preparation and dissemination of this content, two main components should be considered: (a) Information resources characteristics, (b) methods of providing information resource content. Regarding the characteristics of the information resources, the participants stated that the content should be easy to understand, and specific attention should be paid to the characteristics such as the level of literacy, cultural issues, being rural or urban, simplicity and quality of content for patients. They also stated that the methods of receiving information should be different according to the patients' needs. For example, printed brochures are needed to be used for a person, and films and other social media facilities may be used for others. Anyway, both the type of content and the tool and method of accessing this information are affected by various variables, and family physicians and medical librarians

Table 1. Common areas between medical librarians and family physicians in advancing the goals of the family physician program

\begin{tabular}{|c|c|c|}
\hline Concept & Component & Codes \\
\hline $\begin{array}{l}\text { Scientific and } \\
\text { professional } \\
\text { mastering }\end{array}$ & $\begin{array}{l}\text { Upgrading the } \\
\text { professional } \\
\text { knowledge of family } \\
\text { physicians }\end{array}$ & $\begin{array}{l}\text { Information associated with life style (P1), manner of medication use (P1), ability to understand } \\
\text { the results of tests (P1), understanding the basic principles of family health (P2), identification and } \\
\text { control of mental and physical health (P2), harmful factors in environment (P2), interpretation of } \\
\text { premarital routine tests (P2), epidemiological study of diseases (P3), recognition of various diseases } \\
\text { (P3), recognition of different cultures (P4), knowledge on common diseases (P5), recognition of } \\
\text { communication skills (P5), how to work in groups (P5), information about specialized medical groups } \\
\text { (P5), disease tracking (P7), patient screening (P10), understanding of diseases and patients (P10), } \\
\text { information associated with the use of medication in families (P10), updating of clinical information of } \\
\text { physicians (P10) }\end{array}$ \\
\hline \multirow{2}{*}{$\begin{array}{l}\text { Upgrading } \\
\text { research } \\
\text { methodology }\end{array}$} & $\begin{array}{l}\text { Understanding the } \\
\text { research process }\end{array}$ & $\begin{array}{l}\text { Familiarization with research process (P2), conducting research in specific fields (P3), contribution to } \\
\text { research (P5), performing systematic research (P5), family physician research associate (P5) }\end{array}$ \\
\hline & Research prerequisites & $\begin{array}{l}\text { Need for individual education (P10), recognition of information needs (P5), recognition of different } \\
\text { databases (P5), recognition of new technology in conducting research (P8), unwillingness to conduct } \\
\text { research (P10) }\end{array}$ \\
\hline \multirow[t]{2}{*}{$\begin{array}{l}\text { Improving } \\
\text { information } \\
\text { literacy }\end{array}$} & $\begin{array}{l}\text { Correct information } \\
\text { seeking }\end{array}$ & $\begin{array}{l}\text { Help to search databases (P2), understanding how to use modern technology to access information } \\
\text { (P5), finding information sources (P6), evaluation of information resources (P7), ability to search in } \\
\text { specific topics (P10), searching in the field of work tasks (P10), correct information (P3) }\end{array}$ \\
\hline & Search-related factors & $\begin{array}{l}\text { Searching for resources by others (P10), unwillingness to search resources (P10), lack of knowledge } \\
\text { about the benefits of searching (P10), methods of updating information by physicians themselves (P3) }\end{array}$ \\
\hline \multirow[t]{2}{*}{$\begin{array}{l}\text { Education } \\
\text { information } \\
\text { resource } \\
\text { content }\end{array}$} & $\begin{array}{l}\text { Information resources } \\
\text { characteristics }\end{array}$ & $\begin{array}{l}\text { Comprehensibility of patient training brochures (P1), impact of residence location in the provision of } \\
\text { information resources for patients (P1), patient training through images (P1), literacy and knowledge of } \\
\text { people in the dissemination of information (P7), simplification of information for patients (P7), updating } \\
\text { information resources for patients (P7), quality of information resources for patient training (P9), } \\
\text { providing useful information to patients (P7) }\end{array}$ \\
\hline & $\begin{array}{l}\text { Methods of providing } \\
\text { information resource } \\
\text { content }\end{array}$ & $\begin{array}{l}\text { Variation of patient training information resources (P1), patient training through virtual social } \\
\text { networking (P1), providing patients with suitable information (P4), provision of information resources } \\
\text { for patients in various formats (P7), prioritization of some information resources in patient training (P8), } \\
\text { information of the public of health issues (P9), appropriate information transfer to patients (P10) }\end{array}$ \\
\hline
\end{tabular}


should pay attention to these issues in performing their mission (Table 1).

Findings about strategies of interaction of medical librarians with family physicians to advance the goals of the family physician program resulted in the following four concepts.

\section{Appropriate Policy-making}

Systematic establishment of interaction between medical librarians and family physicians for advancing the goals of the family physician program is called the appropriate policy-making. In this regard, first, the position of medical librarians in the family physician program should be considered, and then the type and extent of cooperation and efforts should be developed and implemented for their mutual understanding. In the meantime, medical librarians should increase their level of knowledge and ability including improving communication skills, mastering the medical terminology, and recognizing all kinds of diseases (Table 2).

\section{Suitability of Training}

Training is essential for improving the patient's health and increasing the quality of the services provided by physicians. The participants stated that in order to achieve this goal, medical librarians should help family physicians in two components.

\section{Diversification of training}

Today, education is very diverse, and physicians as well as patients should be able to benefit from these trainings according to their own circumstances. The participants argued that information resources should be provided in various forms to physicians and they should encourage them to use modern technologies. In addition, the cultural and social issues should be regarded in the provision of information resources for patients. Training is needed to be provided sometimes in groups, sometimes virtually, and sometimes even individually. These conditions can be true for patients as well, and they must benefit from diversity in education depending on their conditions and facilities.

\section{Educational content}

The content of information resources available to patients and physicians should be of high quality. Information resources for patient training should be useful and valid. At the same time, these resources should be up-to-date and accessible to patients easily. Family physicians should also use the latest scientific findings in the prevention, diagnosis, treatment, and rehabilitation process. Medical librarians provide the necessary context for this important issue by providing valid information resources and facilitating access to information (Table 2).

\section{Contribution to Clinical Research}

Targeted and systematic activities of medical librarians to help family physicians in conducting clinical research are called contribution to clinical research. This concept is explained by two components.

Table 2. Strategies of interaction of medical librarians with family physicians to advance the goals of the family physician program

\begin{tabular}{|c|c|c|}
\hline Concept & Component & Codes \\
\hline \multirow[t]{2}{*}{$\begin{array}{l}\text { Appropriate } \\
\text { policy-making }\end{array}$} & $\begin{array}{l}\text { Establishment of } \\
\text { formal interaction }\end{array}$ & $\begin{array}{l}\text { Lack of common understanding (P6), identification of the type of cooperation (P6), preparation of joint } \\
\text { meetings (P7), establishment of formal relations in cooperation (P5), improvement of relationships (P10), } \\
\text { lack of a legal framework for interaction (P6) }\end{array}$ \\
\hline & Effective interaction & $\begin{array}{l}\text { Professionalization of medical librarians (P9), lack of confidence in medical librarians (P9), more } \\
\text { familiarity with medical terms (P9), Enhancing communication skills of medical librarians (P6) }\end{array}$ \\
\hline \multirow[t]{2}{*}{$\begin{array}{l}\text { Suitability of } \\
\text { education }\end{array}$} & $\begin{array}{l}\text { Diversification of } \\
\text { education }\end{array}$ & $\begin{array}{l}\text { Providing information resources in various formats (P7), using modern technologies in teaching } \\
\text { physicians (P9), paying attention to cultural and social issues in the provision of patient training } \\
\text { information resources (P1), group training of physicians (P1), virtual training of physicians (P9), single- } \\
\text { training of physicians (P10) }\end{array}$ \\
\hline & Education content & $\begin{array}{l}\text { Proper response to the physician's information needs (P3), provision of suitable materials for physicians } \\
\text { (P5), identification of information needs of physicians (P9), comprehensibility of patient training } \\
\text { brochures (P1), impact of residential area in the provision of information resources for patients (P1), } \\
\text { training patients through images (P1), considering people's literacy and knowledge in the dissemination } \\
\text { of information (P7), simplifying information for patients (P7), updating information resources for patients } \\
\text { (P7), quality of information resources for patient training (P9) }\end{array}$ \\
\hline \multirow[t]{2}{*}{$\begin{array}{l}\text { Contributing to } \\
\text { clinical research }\end{array}$} & $\begin{array}{l}\text { Information } \\
\text { acquisition } \\
\text { methods }\end{array}$ & $\begin{array}{l}\text { Assistance in searching in the field of job tasks (P10), helping to search in specialized databases (P2), } \\
\text { helping to conduct the research process (P2), contribution in family physician research (P5), evaluating } \\
\text { information resources (P7), training virtual search methods (P10), providing access to databases (P10), } \\
\text { training using different databases (P5) }\end{array}$ \\
\hline & $\begin{array}{l}\text { Clinical research } \\
\text { principles }\end{array}$ & $\begin{array}{l}\text { Research process training (P2), contributing to research in specific fields (P3), research assistance (P5), } \\
\text { collaboration in conducting systematic research (P5), helping physicians recognize knowledge gaps } \\
\text { (P5), training new technologies in conducting research (P8), suitability of research methodology tailored } \\
\text { to the needs of physicians (P10) }\end{array}$ \\
\hline \multirow[t]{2}{*}{$\begin{array}{l}\text { Upgrading } \\
\text { the quality of } \\
\text { patient training }\end{array}$} & $\begin{array}{l}\text { Principles of } \\
\text { information } \\
\text { dissemination }\end{array}$ & $\begin{array}{l}\text { Participation in patient information provision (P7), ability to work with physicians on patient training (P9), } \\
\text { adequate knowledge of the proper dissemination of information among the general public (P10), assistance } \\
\text { in updating information of physicians related to patient training (P10), identification of patient habits (P10) }\end{array}$ \\
\hline & $\begin{array}{l}\text { Information } \\
\text { dissemination tools }\end{array}$ & $\begin{array}{l}\text { Providing appropriate tools for disseminating information for patients (P10), using modern information } \\
\text { dissemination technologies (P8), teaching new technologies to patients (P7) }\end{array}$ \\
\hline
\end{tabular}




\section{Information acquisition methods}

Understanding the proper ways of information acquisition is one of the basic concepts in conducting clinical research by family physicians. The participants stated that they needed medical librarians to find information resources such as libraries and databases. Moreover, the family physicians expected medical librarians to provide access to databases for them.

\section{Principles of clinical research}

In the process of promoting community health, family physicists not only need the scientific findings of others, but they must also perform research themselves. Learning and performing research require special expertise and exploitation of the ability of the expertise such as medical librarians. The participants stated that they had problems in the process of conducting research, research in specific fields, conducting systematic research, identifying knowledge gaps, and benefiting from new technologies in conducting clinical research, and that medical librarians could help them remarkably in this process (Table 2).

\section{Improving the Quality of Patient Training}

Patient training is subject to certain principles and rules and, if not followed, all the efforts of family physicians and health professionals will be eliminated. In patient training, one first needs to know the patients' information needs and then use the appropriate tools for disseminating information among them. The content of these resources, while being up-to-date, should follow the principles of reading materials of health in simple language. Medical librarians should also have the ability to work with physicians in patient training, which is because of the sensitivity of providing patients with services. Furthermore, medical librarians should provide appropriate information in order to better train patients and update the knowledge and skills of family physicians (Table 2).

\section{Discussion}

Since access to and use of clinical information is one of the essential requirements of the scientific and professional mastering of family physicians, they must be able to use the latest scientific findings on the types of diseases, screening of patients, recognition of the basic principles of family health, epidemiological investigation of diseases, and mastering in common diseases. Some studies show that physicians need to be equipped with the latest scientific evidence regarding the scientific and professional mastering and to make accurate clinical decisions. ${ }^{15-17}$ Also, the participants stated that the presence of medical librarians could help them in various research stages. In some studies, emphasis has been placed on performing research by physicians in addition to pointing out the role of medical librarians in the process of health research. ${ }^{18,19}$

Family physicians need help from medical librarians to seek information resources, use new technologies for access to information, evaluate information resources, search for specific topics, search for work tasks, correct information, and information updating practices. Physicians must gain the necessary information literacy skills in order to obtain the best evidence for treatment. ${ }^{20}$ According to different studies, information literacy of physicians is an inevitable necessity. ${ }^{21-23}$ In addition, helping physicians in conducting research and efforts to reduce the level of research anxiety of faculty members, especially clinical faculty members, have been predicted to be among the duties of medical librarians. ${ }^{24}$

High-quality information to improve the health of the general public is one of the main tasks of family physicians. Therefore, the provision and dissemination of this content should focus on two main components: the characteristics of information sources and the ways of provision of the information resources content. Several studies have emphasized the readability, simplicity, and intelligibility of information resources for patients. ${ }^{20,25-27}$ Furthermore, in studies such as Ashrafi-Rizi et al., ${ }^{28}$ developing credible information content for patient training has been considered one of the common responsibilities of medical librarians and healthcare professionals.

Experts believe that the position of medical librarians must first be identified in the family physician program, and then the type and extent of cooperation should be determined, and efforts should be made to mutually understand each other. At the same time, medical librarians need to increase their level of knowledge and ability including upgrading communication skills, more mastering the medical terminology, and recognizing all kinds of diseases. There were enough scientific works to explain, but the study by McGowan ${ }^{29}$ focused on the economic analysis of responding of the medical librarians to the physicians' questions, the results of which and other works can establish the context for interactions between medical librarians and family physicians.

In some studies, the variety of training was emphasized, especially with regard to patients' specific needs for information..$^{30,31}$ At the same time, physicians themselves also need specific training given during their working conditions, lack of time, ability level, etc. and medical librarians should provide this context for them. In patient training, one first needs to know the patients' information needs and then use the appropriate tools for disseminating information among them. Medical librarians should also have the ability to work with physicians in patient training, which is because of the sensitivity of providing patients with services. Furthermore, medical librarians should provide appropriate information in order to better train patients and update the knowledge and skills of family physicians. In some studies, the interaction of medical librarians and healthcare professionals regarding patient training has been emphasized. ${ }^{30-32}$

\section{Conclusion}

In this study, the platform for cooperation between the two professions was identified in four areas including helping physicians in scientific and professional mastering, promoting research methodology, improving information literacy, and the content of information resources for patient training. Moreover, strategies for interaction of medical librarians with family physicians were presented in the frameworks of appropriate 
policy-making, suitability of training, participation in clinical search, and upgrading quality of patient training.

\section{Funding}

This paper has been sponsored by Health Information Technology Research Center, the Deputy of Research and Technology at Isfahan University of Medical Sciences, Isfahan, Iran (Ethics No: IR. Mui.research.rec.1397.216).

\section{Competing Interests}

The authors have declared that no competing interests exist.

\section{Conflicts of Interest}

None.

\section{References}

1. Asadi S. Family physician Assessment implementation based on the model (SWOT) in Iran. J Med Educ Dev. 2014;6:72-77.

2. Shiri M, Asgari H, Talebi M, Karamalian H, Rohani M, Narimani S. Educational needs assessment of family (general) physicians working in rural health centers of Esfahan districts in five domains. Iran J Med Educ. 2011:10:726734 (Article in Persian).

3. Movahedi F, Ashrafi Rizi H, Sharif Moghadam H. Physicians' perception about the role of clinical librarianship at Alzahra Medical Center. J Health Adm. 2014;16:71-81.

4. Habibi S, Farzi J, Lotfollahzadeh R. GPs' Information Seeking Behavior in Ardabil and Their Approach towards Electronic Sources. J Ardabil Univ Med Sci. 2008:8:136-141.

5. Rahimianfar AA, Hakimian R, Salimi T. Assessment of information seeking behavior of nurses in academic hospitals of Yazd. Health Inf Manage. 2014;10:706

6. Papi A, Ghazavi R, Moradi S. The awareness and use of electronic information resources by physicians in educational hospitals. Health Inf Manage. 2015;11:712-727.

7. Ciarlo G, Liebl P, Zell J, Fessler J, Koester M, Ruetters D, et al. Information needs of oncologists, general practitioners and other professionals caring for patients with cancer. Eur J Cancer Care (Engl). 2016;25:1015-23.

8. Traver M, Basagoiti I, Martinez-Millana A, Fernandez-Llatas C, Traver $\checkmark$. Experiences of a general practitioner in the daily practice about Digital Health Literacy. The real needs. Conf Proc IEEE Eng Med Biol Soc. 2016;2016:5644-5647.

9. Bryant SL. The information needs and information seeking behaviour of family doctors. Health Info Libr J. 2004;21:84-93.

10. Grol R, Grimshaw J. From best evidence to best practice: effective implementation of change in patients' care. Lancet 2003;362:1225-1230.

11. Manavi S, Olyaee Manesh A, Yazdani S, Shams L, Nasiri T, Shirvani A, et al. Model for implementing evidence based health care system in Iran. Iran J Public Health. 2013:42:758-766.

12. Dawes M. Critically appraised topics and evidence-based medicine journals. Singapore Med J. 2005;46:442-448; quiz 449.

13. Shahrzadi L, Ashrafi-rizi H. Health information consulting: key role of medical librarians. J Med Educ Dev. 2016:9:1-4

14. Hodhodinezhad N, Ashrafi-rizi H, Shahrzadi L, Soleymani M. Effect of using social marketing techniques on the knowledge and attitudes of students and faculty members of isfahan university of medical sciences to the medical librarianship services. J Health Adm. 2016;19:31-42.

15. Hariri N. Principles and methods of qualitative research. Kerman: Islamic Azad University, Science and Research Branch of Tehran; 2016.

16. Sahapong S, Manmart L, Ayuvat D, Potisat S. A systematic review of the roles and competencies of medical information professionals(Mips) in evidence-based medicine in Thailand; 2006. p. 426-435.

17. Schuers M, Griffon N, Kerdelhue G, Foubert Q, Mercier A, Darmoni SJ. Behavior and attitudes of residents and general practitioners in searching for health information: from intention to practice. Int J Med Inform. 2016;89:9-14.

18. Ashrafi-Rizi H, Fateme Z, Khorasgani ZG, Kazempour Z, Imani ST. Barriers to research activities from the perspective of the students of Isfahan University of Medical Sciences. Acta Inform Med. 2015;23:155-159.

19. Ashrafi-Rizi H, Najafi NS, Kazempour Z, Taheri B. Research self-efficacy among students of Isfahan University of Medical Sciences. J Educ Health Promot. 2015:4:26.

20. Cedars BE, Cohen AJ, Fergus KB, Baradaran N, Ndoye M, Kamal P, et al. Qualitative analysis of the content found in online discussion boards for urethral stricture disease and urethroplasty. Urology 2019;130:155-161.

21. Farokhzadian J, Ahmadian L, Khajouei R, Mangolian Shahrbabaki P. Information literacy and training needs of nursing managers for evidencebased practice. Iran J Nurs. 2016;29:43-56.

22. Kalavani A, Kazerani M, Shekofteh M. Evaluation of SBMU residents' knowledge and use of evidence-based medical databases and concepts. J Payavard Salamat 2018;12:34-43.

23. Ross J. Information literacy for evidence-based practice in perianesthesia nurses: readiness for evidence-based practice. J Perianesth Nurs. 2010;25:64-70

24. Ashrafi-Rizi H, Zarmehr F, Bahrami S, Ghazavi-Khorasgani Z, Kazempour Z, Shahrzadi L. Study on research anxiety among faculty members of Isfahan university of medical sciences. Mater Sociomed. 2014;26:356-359.

25. Abu-Heija AA, Shatta M, Ajam M, Abu-Heija U, Imran N, Levine D. Quantitative readability assessment of the internal medicine online patient information on Annals.org. Cureus 2019;11:e4184

26. Alfonso AR, DeMitchell-Rodriguez EM, Ramly EP, Noel DY, Levy-Lambert D, Wang MM, et al. Assessment of American cleft palate-craniofacial association-approved teams' websites for patient-oriented content and readability. Cleft Palate Craniofac J. 2019:56:1213-1219.

27. Yiu A, Ng KK, Lee VW, Bajorek BV. Evaluating the understandability and actionability of web-based education materials for patients taking non-vitamin Koral anticoagulants. Ther Innov Regul Sci. 2019:2168479019849878.

28. Ashrafi-Rizi H, Shahrzadi L, Dehghani-Champiri Z. Identification of patients' rights to benefit from consumer health information services: a Delphi study. J Educ Health Promot. 2019:8:102

29. McGowan J, Hogg W, Zhong J, Zhao X. A cost-consequences analysis of a primary care librarian question and answering service. PloS One 2012;7:e33837

30. Truccolo I. Providing patient information and education in practice: the role of the health librarian. Health Info Libr J. 2016:33:161-166.

31. Zhu Y, Ghajar M, Mitre E. SHARE: spreading health awareness with resources and education -- librarians' role in patient education, a case study. J Hosp Librariansh. 2016;16:319-327.

32. Sollenberger JF, Holloway RG Jr. The evolving role and value of libraries and librarians in health care. JAMA 2013;310:1231-1232.

This work is licensed under a Creative Commons Attribution-NonCommercial 3.0 Unported License which allows users to read, copy, distribute and make derivative works for non-commercial purposes from the material, as long as the author of the original work is cited properly. 